\title{
Diagnóstico ambiental da sub-bacia hidrográfica do Rio Apeú através de fatores geoambientais e climáticos
}

O presente trabalho teve como objetivo analisar o uso e ocupação do solo, a morfometria, a precipitação e a vulnerabilidade ambiental na sub-bacia hidrográfica do rio Apeú, por meio de geotecnologias. O trabalho foi desenvolvido na sub-bacia hidrográfica do rio Apeú que está localizada na região nordeste do Estado do Pará. Foram utilizados os softwares livres QGIS (para o PDI, elaboração dos mapas temáticos) e o RStudio para extração dos dados de precipitação. Por meio da morfometria a SBHRA apresentar forma retangular e alongada, conferindo à sub-bacia baixa suscetibilidade a ocorrências de enchentes. Enquanto que o resultado de uso e ocupação mostraram que 55,25\% da SBHRA é composta por vegetação densa e secundária, seguida por 27,04\% representada por pastagem e culturas e $16,93 \%$ de solo exposto. A análise integrada das variáveis geoambientais analisadas, permitiram a elaboração do mapa de vulnerabilidade ambiental da SBHRA. Permitindo observar que, a SBHRA encontra-se com maiores graus de vulnerabilidades baixos e muito baixos (65,27\%). Porém, é nítido por meio da representação cartográfica da vulnerabilidade, uma distribuição acentuada dos fragmentos de vulnerabilidade médio (22,47\%), principalmente correlacionados as classes de vegetação rasteira, distribuídas quase sempre próximos às áreas de vegetação, seguida pela distribuição da vulnerabilidade alta (11,26\%), correlacionada com às áreas antrópicas. Assim, conclui-se que estudos relacionados a vulnerabilidade ambiental favorecem as tomadas de decisões frente a conservação e sustentabilidade dos recursos naturais, levando em consideração a capacidade de suporte de cada variável dentro do ecossistema, relacionadas principalmente as características especificas de cada ambiente natural.

\section{Environmental diagnosis of the hydrographic sub-basin of the Apeú River through geoenvironmental and climatic factors}

\begin{abstract}
The present work had as objective to analyze the use and occupation of the soil, the morphometry, the precipitation and environmental vulnerability in the hydrographic sub-basin of the Apeú River athwart geotechnologies. The work was developed in the hydrographic sub-basin of the Apeú River which is located in the northeast region of Pará. Free software QGIS (for the PDI, preparation of thematic maps) and RStudio were used for extracting precipitation data. Through morphometry, SBHRA has a rectangular shape and elongated, giving the sub-basin low susceptibility to occurrences of floods. While the result of use and occupation showed that $55.25 \%$ of SBHRA is composed of dense vegetation and secondary followed by $27.04 \%$ represented by pasture and crops and $16.93 \%$ exposed soil. The analysis integration of the geoenvironmental variables analyzed, allowed the elaboration of the vulnerability map SBHRA's environmental policy. Allowing to observe that, SBHRA is with higher degrees of low and very low vulnerabilities (65.27\%). However, it is clear through the cartographic representation of the vulnerability, a marked distribution of fragments of average vulnerability $(22.47 \%)$, mainly correlated to the classes of undergrowth distributed almost always close to the vegetation areas followed by the distribution of high vulnerability $(11.26 \%)$, correlated with the areas anthropic. So, it is concluded that studies related to environmental vulnerability favor decisions regarding the conservation and sustainability of natural resources taking into account the support capacity of each variable within the ecosystem, mainly related to the specific characteristics of each natural environment.
\end{abstract}

Keywords: Morphometry; Use of the Soil; Precipitation; Environmental Vulnerability.

Topic: Engenharia Ambiental

Reviewed anonymously in the process of blind peer.
Received: 04/03/2020

Approved: 18/04/2020
Emerson Renato Maciel da Silva (iD Universidade Federal do Pará, Brasil http://lattes.cnpq.br/5581525631767986 http://orcid.org/0000-0001-8643-0826 emersonrvs255@gmail.com

Edson José Paulino da Rocha (ib Universidade Federal do Pará, Brasil http://lattes.cnpq.br/2313369423727020 http://orcid.org/0000-0002-2509-7027 eprocha@ufpa.br

Ivan Carlos da Costa Barbosa

Universidade Federal Rural da Amazônia, Brasil http://lattes.cnpq.br/3888979612130966 http://orcid.org/0000-0002-7358-5789 ivan.barbosa1212@gmail.com

DOI: 10.6008/CBPC2179-6858.2020.003.0013

\author{
Helder José Farias da Silva (10 \\ Universidade Federal do Rio Grande do Norte, Brasil \\ http://lattes.cnpq.br/5716805278952636 \\ http://orcid.org/0000-0002-0044-7270 \\ helderpa@ufrn.edu.br \\ Luiz Gonzaga da Silva Costa (iD) \\ Universidade Federal Rural da Amazônia, Brasil \\ http://lattes.cnpq.br/8061175054495441 \\ http://orcid.org/0000-0002-2701-2939 \\ luizgonzagacosta53@gmail.com
}

Referencing this:

SILVA, E. R. M.; ROCHA, E. J. P.; BARBOSA, I. C. C.; SILVA, H. J. F.; COSTA, L. G. S.. Diagnóstico ambiental da sub-bacia hidrográfica do Rio Apeú através de fatores geoambientais e climáticos. Revista Ibero Americana de Ciências Ambientais, v.11, n.3, p.137-154, 2020. DOI: http://doi.org/10.6008/CBPC2179-6858.2020.003.0013 


\section{INTRODUÇÃO}

As atividades naturais ou antrópicas são responsáveis por promover alterações e mudanças continuas ao meio ambiente e seus recursos naturais, provenientes principalmente pelas formas de uso da terra. Para que se percebam essas mudanças, de acordo com Rodrigues et al. (2019) é necessário se atentar de maneira sistêmica para as vertentes ambientais, sociais e econômicas, objetivando a identificação, o monitoramento a eliminação ou minimização dos fenômenos associados à tais alterações.

Partindo desse pressuposto e, por entender que a eficiência na gestão de recursos naturais deve levar em consideração a interligação dos mesmos, a Lei das Águas (BRASIL, 1997) estabelece em suas diretrizes uma associação entre as gestões ambientais, hídricas e de uso do solo, fazendo com que a bacia hidrográfica assuma um papel crucial como unidade de gestão (SWAROWSKY et al., 2011). Assim, por apresentar componentes que apresentam uma interação e correlacionam-se como a cobertura vegetal, clima, geologia, geomorfologia e rios e, por qualquer impacto em um desses componentes resultarem em alterações ao ambiente, torna-se indiscutível a adoção da bacia hidrográfica como unidade de planejamento e estudos ambientais (SANTOS, 2004; FAUSTINO et al., 2014).

A quantidade de água que chega aos afluentes e rio principal de uma bacia hidrográfica depende fundamentalmente do tamanho da área ocupada pela bacia, do regime de precipitação e da sua espacialização, assim como, das perdas provenientes da evapotranspiração e infiltração. Além disso, a presença da vegetação exerce um papel fundamental em uma bacia hidrográfica, auxiliando nos processos de interceptação da água da chuva, reduzindo a velocidade do escoamento superficial, favorecendo a infiltração que resulta no abastecimento dos lençóis freáticos e corpos d'água (FAUSTINO et al., 2014).

Para Silva et al. (2017), a análise de uso e ocupação do solo, associada as características morfométricas e a precipitação, proporcionam informações a respeito do diagnóstico ambiental da bacia hidrográfica, uma vez que, medidas de proteção à vegetação e de manejo adequado do uso e ocupação do solo favorecem a conservação dos recursos hídricos de uma bacia, seja quantitativamente ou qualitativamente. Além do mais, Santos et al. (2012) e Silva et al. (2016), descrevem que a avaliação do comportamento hidrológico associado ao aumento ou diminuição de impactos ambientais em bacias hidrográficas são obtidas por meio das características morfométricas.

Diante dessas perspectivas, aliadas ao avanço das técnicas de sensoriamento remoto e utilização do geoprocessamento, o levantamento de dados relacionados à precipitação, morfometria e do uso e ocupação do solo, por meio de Sistemas de Informações Geográficas (SIG's) e de imagens SRTM (do inglês, Shuttle Radar Topography Mission), tem contribuído para a extração dessas informações ambientais, favorecendo a interpretação do espaço geográfico e na obtenção de informações espaciais importantes à conservação e gestão dos recursos naturais (FRAGA et al., 2014; SILVA et al., 2016; ALVES et al., 2019; RODRIGUES et al., 2019).

Neste contexto, objetivou-se com este trabalho analisar o uso e ocupação do solo, a morfometria, o comportamento da precipitação e a vulnerabilidade ambiental na sub-bacia hidrográfica do rio Apeú, 
localizada no nordeste do estado do Pará, por meio de geotecnologias, com intuito de fornecer subsídio à gestão dos recursos hídricos, a pesquisadores e demais interessados de áreas correlatas.

\section{MATERIAIS E MÉTODOS}

\section{Caracterização da área de estudo}

A sub-bacia hidrográfica do rio Apeú (SBHRA) está localizada na região nordeste do Estado do Pará (figura 1), ocupando uma área de aproximadamente $320 \mathrm{~km}^{2}$ (VALE, 2017). Está sub-bacia se situa entre os municípios de Castanhal, Santa Isabel do Pará e Inhangapi, sendo sua maior área (aproximadamente 77\%) situada no município de Castanhal (SOUZA, 2011; VALE, 2017).

A SBHRA apresenta em sua área diferentes logradouros, tais como, vilarejos, povoados, fazendas, agrovilas, etc., onde são desenvolvidas atividades rurais e urbanas, tendo como destaque a agricultura, a pecuária e a extração mineral. Recentemente os loteamentos residenciais vem se configurando como principal causador da transformação da paisagem nos limites da sub-bacia (VALE et al., 2017).

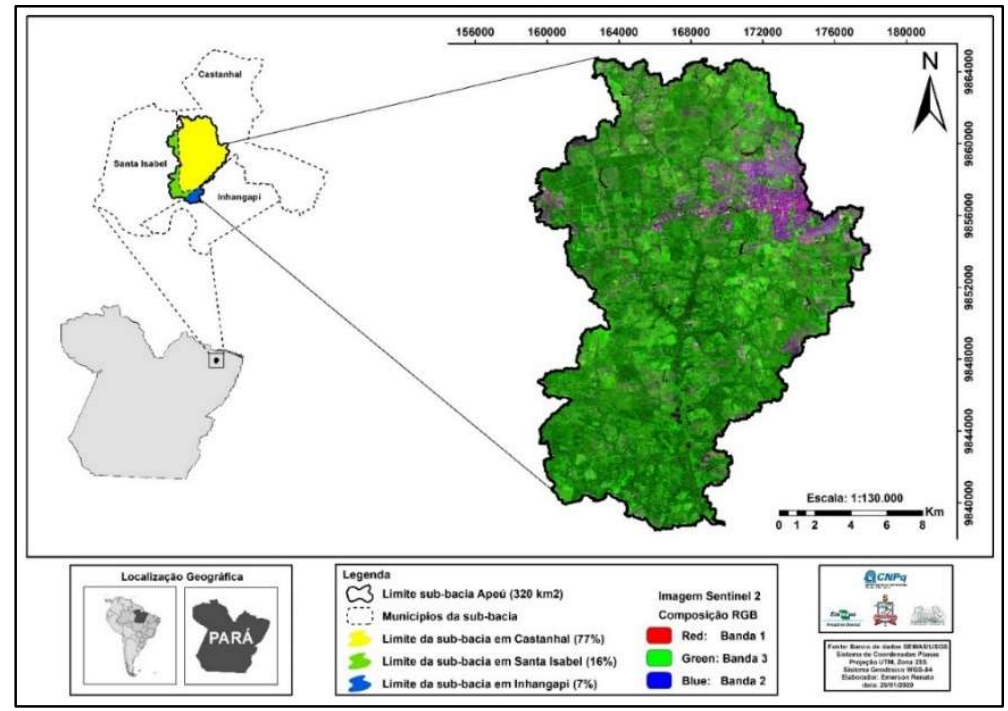

Figura 1: Mapa de localização da sub-bacia hidrográfica do rio Apeú - SBHRA.

De acordo com a classificação de Köppen, a região possui um clima do tipo Af - Clima Tropical Úmido, caracterizada por ocorrências de precipitação durante todos os meses do ano e sem estação seca. Possui uma média climatológica da temperatura do ar, durante o mês mais frio, superior a $18^{\circ} \mathrm{C}$ (ALVARES et al., 2013).

\section{Delimitação e características morfométricas da sub-bacia hidrográfica do rio Apeú}

A delimitação da SBHRA foi realizada a partir dos dados georreferenciados do relevo da área em questão, os quais são derivados de produtos da missão SRTM, com resolução espacial de $30 \mathrm{~m}$, disponibilizado de forma gratuita na base de dados da missão SRTM pela Earth Resources Observation and Science/United States Geological Survey (EROS/USGS). Assim, para realizar o processamento se utilizou a ferramenta TauDEM (do inglês, Terrain Analysis Using Digital Elevation Models), versão 5.3, que se constitui em uma extensão gratuita que pode ser instalada no programa QGIS . 
De posse da delimitação da sub-bacia e dos demais resultados, oriundos desse processo, foram obtidas as variáveis utilizadas para determinação dos índices morfométricos da SBHRA. A morfometria é o ramo da morfologia que analisa o relevo por meio de um conjunto de variáveis e índices quantitativos (FLORENZANO, 2008). Assim, a análise quantitativa das relações entre a fisiografia da bacia e a sua dinâmica hidrológica é definida como o estudo morfométrico de bacias hidrográficas. Sendo de fundamental importância para o entendimento do comportamento hidrológico de uma bacia, uma vez que, as variáveis morfométricas se caracterizam como bons indicadores da capacidade de escoamento superficial (VALE, 2017).

As características morfométricas podem ser divididas em: características da rede de drenagem, do relevo e geométricas (TONELLO, 2005). A análise morfométrica da sub-bacia hidrográfica do rio Apeú foi desenvolvida com base nas características geométricas, de relevo e dos canais de drenagem. Assim, na tabela 1 encontra-se a divisão dos índices morfométricos e respectivas descrições das equações.

Tabela 1: Principais índices das características morfométricas de uma bacia hidrográfica.

\begin{tabular}{|c|c|c|c|}
\hline Índices morfométricos & Equações & Descrição & Fonte \\
\hline \multicolumn{4}{|l|}{ Características Geométricas } \\
\hline $\begin{array}{l}\text { Coeficiente de } \\
\text { Compacidade (Kc) }\end{array}$ & $K c=0,28 \frac{P}{\sqrt{A}}$ & $\begin{array}{l}\mathrm{P}=\text { Perímetro }(\mathrm{km}) \\
\mathrm{A}=\text { Área da bacia }\left(\mathrm{km}^{2}\right)\end{array}$ & Vilela et al. (1975) \\
\hline Fator de forma (F) & $K f=\frac{A}{L^{2}}$ & $\begin{array}{l}\mathrm{A}=\text { Área da bacia }\left(\mathrm{km}^{2}\right) \\
\mathrm{L}=\text { Comprimento da bacia }(\mathrm{km})\end{array}$ & Horton (1945) \\
\hline \multicolumn{4}{|l|}{ Características de Relevo } \\
\hline Amplitude altimétrica (Hm) & $\begin{array}{l}H m \\
=A m a ́ x-A m i ́ n\end{array}$ & $\begin{array}{l}A_{\text {máx }}=\text { Altitude máxima }(\mathrm{m}) \\
A_{\text {min }}=\text { Altitude mínima }(\mathrm{m})\end{array}$ & Strahler (1952) \\
\hline Declividade & - & $\%$ & Embrapa (2013) \\
\hline \multicolumn{4}{|c|}{ Características da Rede de Drenagem } \\
\hline $\begin{array}{l}\text { Densidade de drenagem } \\
\text { (Dd) }\end{array}$ & $D d=\frac{L t}{A}$ & $\begin{array}{l}\text { Lt }=\text { Comprimento total de todos os canais de } \\
\text { drenagem }(\mathrm{km}) \\
\mathrm{A}=\text { Área da bacia }\left(\mathrm{km}^{2}\right)\end{array}$ & Horton (1945) \\
\hline Ordem dos cursos de água & - & Rank hierárquico & Strahler (1952) \\
\hline
\end{tabular}

Fonte: Adaptado de Tonello (2005).

\section{Classificação do uso e ocupação do solo da sub-bacia hidrográfica do rio Apeú}

A classificação é um dos processos fundamentais no processamento digital de imagens, com uma frequente utilização em mapeamentos temáticos, em especifico, na elaboração de mapas de uso e ocupação do solo. O processo de classificação de imagens pode ser realizado de algumas maneiras, entre as quais temse, a classificação visual, automática ou semiautomática (a classificação automática pode ser supervisionada ou não-supervisionada) e a classificação pixel-a-pixel ou contextuais, quando se realiza a segmentação da cena (RIBEIRO et al., 2009).

Para realizar a discriminação dos tipos de uso e ocupação do solo, presentes na SBHRA, foram obtidas imagens do produto do sensor MSI, satélite Sentinel-2, que possui como características ser de órbita heliossíncrona circular, com resolução radiométrica de 12 bits, resolução temporal de 10 dias, resolução espectral de 13 bandas e uma resolução espacial de 10 metros. Seus dados são disponibilizados de maneira gratuita no site da USGS ${ }^{1}$, e a cena selecionada data do dia 25 de junho de 2018 , tendo como critério de

\footnotetext{
${ }^{1}$ https://earthexplorer.usgs.gov
} 
seleção a época de menor cobertura de nuvens, pois favorece os processos de classificação da imagem.

A imagem foi submetida ao método de classificação supervisionado, para o qual, o analista necessita ter conhecimento prévio sobre os alvos para fornecer amostras ao sistema/software (RODRIGUES et al., 2016). Assim, foi realizado o levantamento de oito pontos de referência, por meio de um GPS (Garmin, GPSMAP ${ }^{\oplus}$, série 78), em quatro campanhas entre os anos de 2018 e 2019 (tabela 2).

Tabela 2: Pontos de referência, suas descrições, coordenadas geográficas e campanhas de campo.

\begin{tabular}{|l|l|l|l|l|}
\hline Pontos de referência & Descrições prévias dos alvos & Latitude (S) & Longitude (W) & Campanhas (mês/ano) \\
\hline P1 & Fazenda 01 & $1^{\circ} 13^{\prime} 41^{\prime \prime}$ & $47^{\circ} 58^{\prime} 46.7^{\prime \prime}$ & \multirow{2}{*}{ Setembro/2018 } \\
\hline P2 & Fazenda 01 & $1^{\circ} 13^{\prime} 43.2^{\prime \prime}$ & $47^{\circ} 58^{\prime} 19.8^{\prime \prime}$ & \\
\hline P3 & Balneário Apeú & $1^{\circ} 17^{\prime} 57.4^{\prime \prime}$ & $47^{\circ} 59^{\prime} 6.3^{\prime \prime}$ & \multirow{2}{*}{ Novembro/2018 } \\
\hline P4 & Fazenda 02 & $1^{\circ} 19^{\prime} 37.7^{\prime \prime}$ & $47^{\circ} 58^{\prime} 42.1^{\prime \prime}$ & \\
\hline P5 & Agrovila Boa Vista & $1^{\circ} 21^{\prime} 12.5^{\prime \prime}$ & $47^{\circ} 59^{\prime} 11.8^{\prime \prime}$ & \multirow{2}{*}{ Fevereiro/2019 } \\
\hline P6 & Agrovila Macapazinho & $1^{\circ} 23^{\prime} 24.5^{\prime \prime}$ & $47^{\circ} 59^{\prime} 10.0^{\prime \prime}$ & \\
\hline P8 & Sr. Armando & $1^{\circ} 26^{\prime} 56.3^{\prime \prime}$ & $47^{\circ} 58^{\prime} 38.4^{\prime \prime}$ & \multirow{2}{*}{ Abril/2019 } \\
\hline
\end{tabular}

De posse da imagem, todos os procedimentos de Processamento Digital de Imagens (PDI) foram realizados no software livre QGIS (versão 3.4). Inicialmente a imagem foi submetida aos processos de correções atmosférica e radiométrica, necessários para reduzir os ruídos causados principalmente por agentes atmosféricos durante o processo de captação de informações, por meio do complemento SemiAutomatic Classification Plugin (SCP).

Posteriormente as correções, a imagem foi submetida ao processo de classificação, para o qual foi utilizado o complemento dzetsaka: Classification tool, que possui como principais características a simplicidade e agilidade aliadas à um excelente produto de classificação. Para a classificação foram coletadas um total de 170 amostras (30 amostras para as classes de vegetação densa, vegetação secundária, vegetação rasteira, solo exposto e 50 amostras para classe de corpos d'água), referente as principais classes a serem discriminadas no mapa de uso e ocupação do solo, e aplicado o modelo de classificação mistura gaussians. A validação da classificação foi realizada com base no índice de Kappa, proposto por Landis et al. (1997), com uma variação da acurácia da classificação de 0 a 1 , sendo que cada intervalo do índice possui uma concordância em relação a classificação realizada (tabela 3).

Tabela 3: Valores de referência do Índice Kappa.

\begin{tabular}{|l|l|}
\hline Índice Kappa & Concordância \\
\hline$<0,00$ & Péssima \\
\hline 0,00 a 0,20 & Ruim \\
\hline 0,20 a 0,40 & Razoável \\
\hline 0,40 a 0,60 & Bom \\
\hline 0,60 a 0,80 & Muito Bom \\
\hline 0,80 a 1,00 & Excelente \\
\hline
\end{tabular}

Fonte: Adaptado de Landis et al. (1997).

\section{Dados de precipitação}

Com o intuito de obter informações sobre o comportamento e a espacialização do quantitativo de precipitação dentro dos limites da SBHRA, para o presente trabalho foram utilizados dados mensais do 
produto CHIRPS disponíveis de maneira gratuita em alguns sites ${ }^{2}$. O produto CHIRPS é desenvolvido pelo United States Geological Survey (USGS) e pelo Climate Hazards Group at the University of California, Santa Barbara (UCSB), com resolução espacial de aproximadamente $5 \mathrm{~km}\left(0,05^{\circ} \times 0,05^{\circ}\right)$ e um produto que mescla dados estimados por satélite e observacionais por estações, com dados diários, pentadados e mensais (FUNK et al., 2015).

Para poder realizar a comparação e relação entre as classes de uso do solo e morfometria com o comportamento da precipitação na sub-bacia, foram adquiridos os valores de precipitação do produto CHIRPS para os respectivos anos das campanhas mencionadas anteriormente (2018 e 2019). Para extração dos valores de precipitação foi utilizado linguagem de programação $R$, por meio do software livre Rstudio. De posse dos valores extraídos, no software livre QGIS (versão 3.4), foi realizada a interpolação por Krigagem da precipitação acumulada média, assim como, para os respectivos períodos chuvoso (dezembro a maio) e menos chuvoso (junho a novembro).

\section{Determinação da vulnerabilidade ambiental na sub-bacia hidrográfica do rio Apeú}

Tendo como objetivo obter informações a respeito do atual comportamento, em função dos processos de uso e ocupação do solo, na sub-bacia hidrográfica do rio Apeú (SBHRA), foi elaborado o mapa de vulnerabilidade ambiental da SBHRA. Para o qual, foram utilizados além das informações de mapa do uso e ocupação do solo, morfometria (em especifico as informações de declividades) e a precipitação, os dados de tipo de vegetação, geologia e pedologia.

De acordo com Costa et al. (2006), a importância do tipo de vegetação está relacionada a estrutura das redes e teias alimentares, além do estágio de fitossucessão e a biodiversidade (dados obtidos do Projeto de Conservação e Utilização Sustentável da Diversidade Biológica Brasileira - PROBIO). Enquanto que as variáveis tipo do solo e geologia, obtidos do Instituto Brasileiro de Geografia e Estatística - IBGE do projeto RADAM, relacionam-se com a morfogênese e pedogênese. Por outro lado, a declividade fornece informações a respeito da susceptibilidade à erosão, que tende a ser maior à medida que se aumenta a inclinação do relevo, associando-se a importância da utilização dos dados de precipitação e sua contribuição as alterações do relevo (CREPANI et al., 2001), que foram obtidos através do produto CHIRPS (para os anos de 2018 a 2019).

O cruzamento das variáveis, citadas anteriormente, foi efetuada no software livre QGIS (versão 3.4), por meio da técnica de álgebras de mapas, para identificação da intensidade e distribuição da vulnerabilidade ambiental na área da SBHRA. Onde, a operação dos dados foi realizada com base no modelo estabelecido por Crepani et al. (2001), onde o grau de vulnerabilidade atribuído para cada variável é distribuído em uma escala de 1,0 a 3,0. Onde valores de 1,0 indicam um ambiente estável; valores próximos de 2,0 indicam situações intermediárias, ou seja, ambientes com equilíbrio/intermediário; e a instabilidade está associada ao valor 3,0, indicando ambientes instáveis, caraterizados pelas alterações do relevo (tabela 4).

\footnotetext{
$2 \mathrm{ftp}$ ///chg-ftpout.geog.ucsb.edu/pub/org/chg/products/CHIRPS-2.0/global_monthly/tifs/ earlywarning.usgs.gov/fews/datadownloads/Global/CHIRPS\%202.0.
} 
Tabela 4: Graus de vulnerabilidades das variáveis geoambientais da sub-bacia hidrográfica do rio Apeú.

\begin{tabular}{|l|l|l|l|l|l|l|l|}
\hline Pedologia & GV* & Uso do Solo** & GV & $\begin{array}{l}\text { Precipitação } \\
\text { (mm/ano) }\end{array}$ & GV & Declividade & GV \\
\hline Latossolo & 1 & VD & 1 & $3400-3600$ & 2 & $0-2$ & 1 \\
\hline Geologia & & VS & 1,5 & Vegetação & & $2-6$ & 1,5 \\
\hline Grupo Barreiras & 2 & VR & 2 & Floresta Densa Aluvial & 1 & $6-20$ & 2 \\
\hline Cobertura Detrito-Laterítica Pleistocênica & 3 & SE & 3 & Vegetação Secundária & 1,5 & $20-50$ & 2,5 \\
\hline & & & & Área Antropizada & 3 & & \\
\hline
\end{tabular}

*GV: Grau de vulnerabilidade; **VD: vegetação densa, VS: Vegetação secundária, VR: Vegetação rasteira, SE: Solo exposto. Fonte: adaptado de Crepani et al. (2001).

Após o cruzamento das variáveis geoambientais selecionadas (pedologia, geologia, declividade, uso do solo, precipitação e tipo de vegetação), foi calculada a média aritmética dos valores de vulnerabilidade de cada variável. Este resultado aritmético foi organizado em cinco classes de vulnerabilidade ambiental, como pode ser visto na tabela 5 .

Tabela 5: Média aritmética para as classes de vulnerabilidade ambiental.

\begin{tabular}{|c|c|c|c|}
\hline \multicolumn{3}{|c|}{ Média } & \multirow{2}{*}{$\begin{array}{l}\text { Vulnerabilidade Ambiental } \\
\text { Muito alta }\end{array}$} \\
\hline b $\subseteq T$ & $2,7-3,0$ & $\downarrow \widetilde{\Omega}$ & \\
\hline m & $2,3-2,6$ & 吕 & Alta \\
\hline 管 & $1,8-2,2$ & $\overline{\bar{\sigma}}$ & Média \\
\hline$\underline{\underline{\sigma}}$ & $1,4-1,7$ & $B$ & Baixa \\
\hline $\bar{\sigma}$ & $1-1,4$ & m & Muito baixa \\
\hline
\end{tabular}

Para o cálculo final da vulnerabilidade ambiental foi aplicado o método de ponderação de fatores, permitindo ao analista determinar importância relativa de cada fator dentro da área de estudo (COSTA et al., 2006). Ainda segundo Costa et al. (2006), o maior peso atribuído a variável uso do solo em relação as demais, está associado ao objetivo de demonstrar melhor as especificidades de uma determinada área em relação ao grau e tipo de antropização, conforme demonstrado na equação abaixo:

Vulnerabilidade Ambiental = 0,1*Pedologia + 0,1*Precipitação + 0.1*Vegetação + 0,1*Declividade +

$$
0,1 * \text { Geologia }+0,50 * \text { Uso do Solo }
$$

\section{RESULTADOS E DISCUSSÃO}

\section{Características morfométricas da sub-bacia hidrográfica do rio Apeú}

As características morfométricas da SBHRA são apresentadas na tabela 6. Nota-se que os resultados apresentaram similaridade com os obtidos por Vale (2017), que desenvolveu o trabalho de análise geoambiental da bacia hidrográfica do rio Apeú, visando o subsídio ao planejamento ambiental da sub-bacia.

Diante disso, pode ser observado na tabela 6, que a sub-bacia do rio Apeú possui uma área de aproximadamente $320 \mathrm{Km}^{2}$ e ocupa um perímetro de 152,54 quilômetros, tendo como rio principal o igarapé Apeú, que segundo a classificação hierárquica proposta por Strahler (1952), é de 5a ordem. O processo de classificação dos cursos d'água da rede de drenagem de uma bacia é denominado de hierarquia fluvial e, tem como finalidade facilitar os estudos morfométricos sobre a respectiva bacia (VILELA FILHO et al., 2005; MENDES, 2018).

Por meio do coeficiente de compacidade e o fator de forma encontrados para a sub-bacia do rio Apeú, respectivamente 1,47 e 0,23, demonstra-se que a bacia apresenta forma retangular e alongada, 
conferindo à sub-bacia baixa suscetibilidade a ocorrências de enchentes, excluindo casos de eventos extremos de precipitação. Ao analisar o coeficiente de compacidade e o fator de forma da bacia hidrográfica do Igarapé da Prata, no município de Capitão do Poço, noroeste do Estado do Pará, Rodrigues et al. (2016) encontraram um formato mais alongado favorecendo o escoamento na bacia.

Tabela 6: Valores dos índices morfométricos da sub-bacia do rio Apeú.

\begin{tabular}{|l|l|l|}
\hline Índices & Resultados & Unidades \\
\hline Área total (A) & 320 & $\mathrm{Km}^{2}$ \\
\hline Perímetro total (P) & 152,54 & $\mathrm{Km}^{*}$ \\
\hline Coeficiente de compacidade (Kc) & 1,47 & $-^{*}$ \\
\hline Fator de forma (Kf) & 0,23 & - \\
\hline Amplitude altimétrica (Hm) & 65 & $\mathrm{~m}$ \\
\hline Densidade de drenagem (Dd) & 0,47 & $\mathrm{Km}^{-} \mathrm{Km}^{2}$ \\
\hline Hierarquia & 5 a Ordem & - \\
\hline Padrão de drenagem & Dendrítica & - \\
\hline
\end{tabular}

*Índices adimensionais.

Para uma bacia ou sub-bacia, o sistema de drenagem é constituído pelo canal principal e seus afluentes. O padrão de drenagem vai depender da estrutura geológica do local, tipo de solo, topografia, clima e irá influenciar no comportamento hidrológico de toda área da sub-bacia. Assim, o padrão encontrado para a sub-bacia do rio Apeú é o dendrítico. Este tipo de drenagem é característico de um controle estrutural realizado por sedimentos horizontais ou rochas cristalinas homogêneas (SUMMERFIELD, 1991).

Conforme Christofoletti (1980), a associação entre a vegetação, o clima e a sua composição litológica resultam na densidade de drenagem, e influência diretamente na dinâmica de uma bacia hidrográfica. Este índice, segundo Villela et al. (1975), varia de 0,5 km/ $\mathrm{km}^{2}$ (bacias mal drenadas) a 3,5 km/ $\mathrm{km}^{2}$ (bacias bem drenadas). A sub-bacia hidrográfica do rio Apeú apresenta uma drenagem pobre, com uma densidade de drenagem de $0,47 \mathrm{~km} / \mathrm{km}^{2}$, ou seja, possui capacidade mediana de gerar novos cursos d'água, caracterizando um escoamento superficial razoavelmente baixo (VILLELA et al., 1975; BELTRAME, 1995; LOLLO, 1995).

Segundo Mendes (2018) as características morfométricas relacionadas ao relevo são importantes por estarem diretamente ligadas as características do escoamento superficial e da drenagem de uma bacia. Pois o conhecimento do escoamento é de elevada significância quanto ao ciclo hidrológico, por se referir ao transporte da água na superfície terrestre, sabendo que normalmente os estudos hidrológicos se referem ao aproveitamento da água superficial e a proteção quanto aos efeitos desse deslocamento (MENDES, 2018). Assim, é possível observar na figura 2 a hipsometria da sub-bacia do rio Apeú e, que as partes mais elevadas da sub-bacia se encontram em suas cabeceiras e extremidades, favorecendo o escoamento das partes mais altas para o leito principal que é o rio Apeú.

A tabela 7 apresenta a porcentagem de ocorrência para cada faixa de altitude na área em estudo. É possível verificar que cerca de $64,45 \%$ do relevo do local atinge até $40 \mathrm{~m}$ de altitude. Em termos de características de relevo a bacia do rio Apeú apresenta altitude mínima $\left(A_{\min }\right)$ de 1 m e altitude máxima $\left(A_{\text {máx }}\right)$ de $66 \mathrm{~m}$. A amplitude altimétrica $(\mathrm{Hm})$ calculada é de $65 \mathrm{~m}$, o que indica que está sub-bacia apresenta relevo plano. 


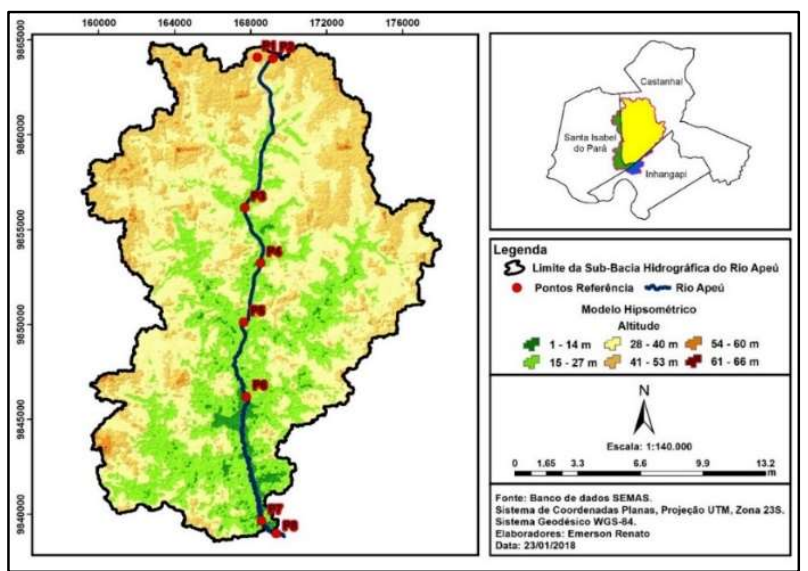

Figura 2: Mapa Hipsométrico da sub-bacia hidrográfica do rio Apeú - SBHRA.

Tabela 7: Características do relevo da sub-bacia hidrográfica do rio Apeú - SBHRA.

\begin{tabular}{|l|l|l|}
\hline Intervalos de Altitude & No de ocorrências & Porcentagem de ocorrência (\%) \\
\hline $1-14 \mathrm{~m}$ & 299 & 15.48 \\
\hline $15-27 \mathrm{~m}$ & 350 & 18.12 \\
\hline $28-40 \mathrm{~m}$ & 596 & 30.85 \\
\hline $41-53 \mathrm{~m}$ & 506 & 26.19 \\
\hline $54-60 \mathrm{~m}$ & 133 & 6.88 \\
\hline $61-66 \mathrm{~m}$ & 48 & 2.48 \\
\hline Total & 1.932 & $100 \%$ \\
\hline
\end{tabular}

Para Castro et al. (2001), a importância da altitude de uma bacia está diretamente relacionada à quantidade de radiação que a bacia recebe, refletindo na evapotranspiração, temperatura e precipitação. Assim, a análise hipsometria de uma bacia hidrográfica é um fator muito importante, pois as informações das altitudes iram contribuir para o entendimento da dinâmica da temperatura (evapotranspiração) e nos efeitos da precipitação (escoamento superficial e infiltração) na região onde se encontra a bacia (VILLELA et al., 1975).

A figura 3 apresenta a declividade da sub-bacia do rio Apeú. Por meio do mapa percebe-se que a subbacia em sua grande maioria é plana e suave-ondulada com declividades variando de 0 a $45 \%$, de acordo com os limites estabelecidos pela Empresa Brasileira de Pesquisa Agropecuária (EMBRAPA, 2013), nas regiões com maior declividade os valores variam de 8 a 20\% (ondulado) e 20 a 40\% (forte-ondulado). Logo, esperase uma menor velocidade de escoamento e tempo de concentração (Tc) maior (MENDES, 2018).

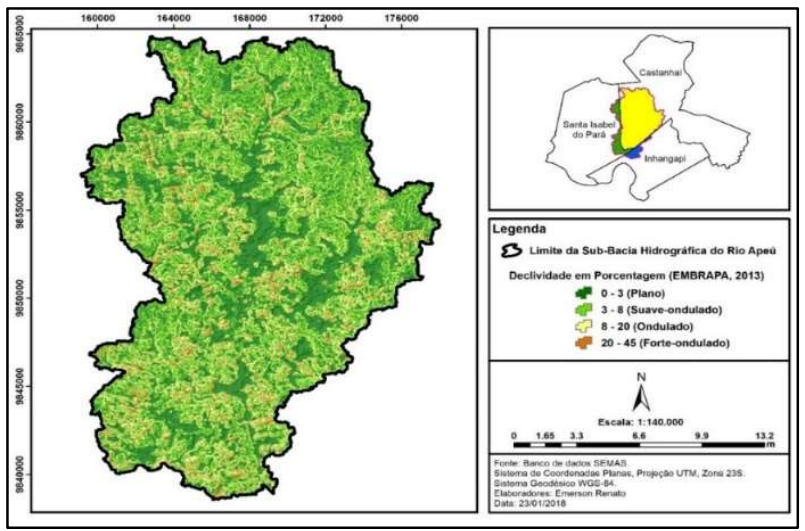

Figura 3: Mapa de declividade da sub-bacia hidrográfica do rio Apeú - SBHRA.

Para realizar o planejamento e manejo adequado do uso e ocupação em uma bacia é fundamental o 
conhecimento das áreas elevadas e declivosas (SANTOS et al., 2007). Partindo desse ponto de vista, Feitosa et al. (2011) elucidam que a bacias com baixas declividades contribuem para uma maior resistência à ação da precipitação, levando à maior estabilidade do solo e a diminuição dos riscos de erosão.

\section{Uso e ocupação do solo da sub-bacia hidrográfica do rio Apeú}

A figura 4 apresenta o mapa de uso e ocupação do solo presente na SBHRA. É importante ressaltar que o resultado referente à validação da classificação apresentou índice Kappa de aproximadamente 0,90, demonstrando uma alta precisão no processo de classificação da imagem de satélite. Foram identificadas cinco classes de uso e ocupação na ABHRA, são estas: vegetação densa, vegetação secundária, vegetação rasteira (formada por pastagens e culturas), solo exposto (composta por áreas urbanas e solo sem cobertura vegetal) e corpos d'água (lagos e açudes).

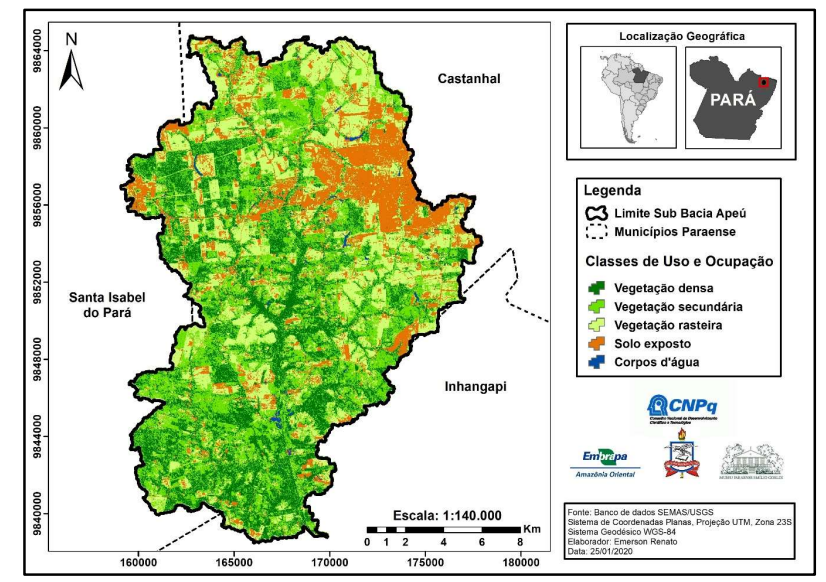

Figura 4: Mapa de uso e ocupação do solo da sub-bacia hidrográfica do rio Apeú - SBHRA.

Uma análise qualitativa do mapa (figura 4) mostra que a vegetação rasteira (pastagem e culturas) e solo exposto (área urbana e solo sem cobertura vegetal) são usos com presenças acentuadas na bacia. As visitas em campo comprovaram as informações expostas no mapa, onde foi possível observar uma vasta presença de pastagem, principalmente na região norte/nordeste da bacia, assim como o destaque para grande presença de área urbana oriunda do núcleo urbano do município de Castanhal/PA.

A classe de solo exposto, referente a área urbana, são reflexos do histórico de ocupação (final da década de 80 e início da década de 90) oriundos da construção dos primeiros conjuntos habitacionais às margens da Avenida Barão do Rio Branco que, atualmente promove o acesso ao distrito do Apeú ao centro urbano de Castanhal. Outros aspectos que contribuíram para o crescimento das áreas urbanas nos limites da sub-bacia são resultados das vendas de propriedades rurais, levando aos pequenos produtores se estabelecerem em habitações nas áreas periféricas dos pequenos centros urbanos de Santa Izabel e Castanhal, principalmente, nos atuais distritos de Apeú e Americano, o que acarretou no crescimento da área urbana destes municípios (VALE et al., 2017).

$\mathrm{O}$ avanço das áreas urbanas, normalmente sem o acompanhamento de infraestrutura, reflete na capacidade de infiltração de água no solo, levando ao aumento do escoamento superficial, a concentração das enxurradas e a ocorrência de cheias. Além disso, a urbanização afeta o ciclo hidrológico, interferindo no 
armazenamento e nos percursos das águas (CHRISTOFOLETTI, 2012).

A presença da pastagem está associada à principal atividade econômica desenvolvida na área da subbacia, em destaque a pecuária do gado de corte e produção de leite, pois a maioria das fazendas (cerca de 80\%) tem estas práticas como principal atividade produtiva (VALE et al., 2017). Os referidos autores ainda descrevem que as principais culturas desenvolvidas na sub-bacia são de culturas temporárias como o feijão, a mandioca, o milho, e de culturas perenes como o mamão, a pimenta-do-reino e o dendê.

As classes de vegetação densa e vegetação secundária apresentaram-se com maior predominância na área em estudo em relação as demais, principalmente na porção sul da bacia e no trecho do rio, como mostra a figura 4. Em relação à vegetação densa e secundária, apesar de serem visivelmente mais presentes, é possível observar que são suprimidas pelas classes de vegetação rasteira e solo exposto, o que se configura em um cenário ambientalmente preocupante. Conforme resultados encontrados nas pesquisas de Rodrigues et al. (2019) e Alves et al. (2019), uma vez que, a presença de vegetação favorece a proteção dos recursos hídricos e do solo frente a contaminação, descompactação de partículas do solo e processos erosivos. Também foi realizada uma análise quantitativa sobre as formas de uso e ocupação da sub-bacia, conforme apresentado na tabela 8, corroborando ao descrito na análise qualitativa do uso e ocupação.

Tabela 8: Quantificação das classes de uso e ocupação do solo na sub-bacia hidrográfica do rio Apeú - SBHRA.

\begin{tabular}{|l|l|l|}
\hline Classes de Uso e Ocupação & Área $\mathbf{( k m}^{\mathbf{2}} \mathbf{)}$ & Área (\%) \\
\hline Vegetação densa & 70,01 & 22.94 \\
\hline Vegetação secundária & 98,61 & 32,31 \\
\hline Vegetação rasteira & 82,52 & 27,04 \\
\hline Solo exposto & 51,66 & 16,93 \\
\hline Corpos d'água & 2,40 & 0.79 \\
\hline Total & 305,20 & 100 \\
\hline
\end{tabular}

Segundo o Novo Código Florestal é recomendado que a área de vegetação em uma propriedade ocupe aproximadamente $20 \%$ do valor da área (BRASIL, 2012). Dessa maneira, por meio da tabela 8 e figura 4, pode-se afirmar que a sub-bacia do rio Apeú não apresenta déficit de vegetação, isto porque apresenta uma área de vegetação densa de aproximadamente $22,94 \%$ e vegetação secundária de $32,31 \%$. Isso demonstra que a sub-bacia apresenta áreas em processos de sucessão, pois de acordo com a Resolução $\mathrm{N}^{\circ}$ 243 de 2010, do Conselho Nacional do Meio Ambiente (CONAMA), a vegetação secundária resulta dos processos naturais de sucessão, após a remoção/supressão total ou parcial da vegetação primária por ações antrópicas ou causas naturais. Supressão essa, encontrada em trabalhos já realizados na sub-bacia do Apeú, como de Vale et al. (2017) e Vale (2017), em que através da análise multitemporal do uso e ocupação observaram uma redução da vegetação de 49,93\% (em 1985), para 36,58\% (em 2000) e 20,21\% (em 2015).

Porém, analisando a tabela 8 , observa-se que as classes de vegetação rasteira (pastagem e culturas) e solo exposto (área urbana e solo sem cobertura vegetal) somam aproximadamente $44 \%$ da área da bacia, situadas predominantemente na porção norte/nordeste da bacia (regiões em que possuem nascentes). Caracterizando-se como áreas com ausência de vegetação, comprometendo a qualidade ambiental do ambiente resultando na degradação ambiental do mesmo (RODRIGUES et al., 2019).

Na figura 5 é apresentado o resultado do mapeamento das áreas de preservação permanente (APP) 
na bacia, levando em consideração os pontos de referências levantados em campo. Foi utilizado como referência os limites propostos pelo Código Florestal, que estabelece em suas diretrizes limites de APP para nascentes um raio de 50 metros e para cursos d'água que tenham de 10 a 50 metros de larguras uma APP de 50 metros (BRASIL, 2012).

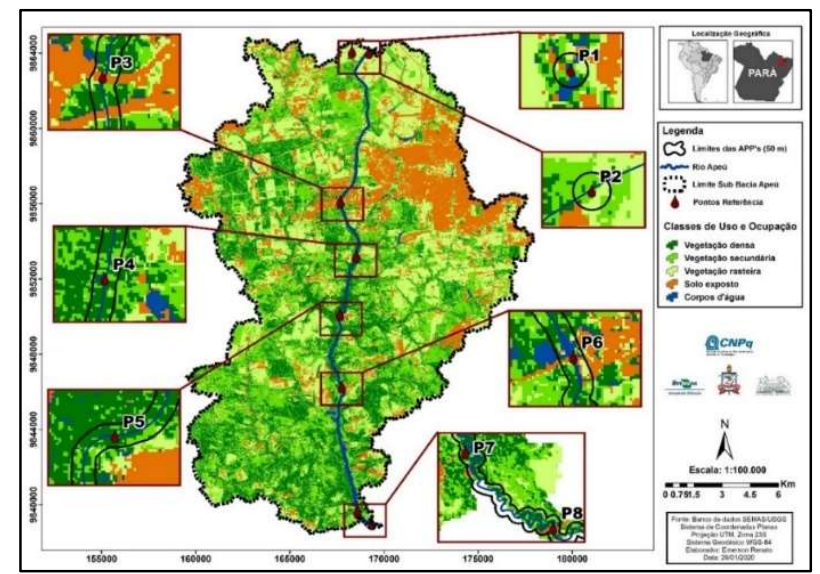

Figura 5: Descrição dos principais tipos de uso dos pontos de referência na sub-bacia hidrográfica do rio Apeú SBHRA.

Verifica-se nos pontos 1 e 2 regiões críticas (com menos cobertura vegetal) e uma predominância de vegetação as margens do rio Apeú a partir do quarto ponto de referência seguindo em direção à foz do rio Apeú no município de Inhangapi (tabela 9). Silva et al. (2017), ponderam que a vegetação exerce influência direta na qualidade das águas, nos arredores da bacia e áreas próximas aos cursos d'água.

Nos pontos de referência 1 e 2, encontram-se as nascentes pertencentes ao curso d'água do rio Apeú. Observa-se, por meio da figura 5 e da tabela 9, a presença das classes de vegetação rasteira (VR) e solo exposto (SE) nos limites da área de preservação permanente, onde deveria ser composta por vegetação (mata ciliar/ripária), respeitando as normas do código florestal.

Tabela 9: Descrição das principais classes por ponto de referência em relação a APP de 50m.

\begin{tabular}{|l|l|}
\hline Pontos de referência & Classes de Uso e Ocupação nas APP's \\
\hline P1 & VR+SE \\
\hline P2 & VS+VR+SE \\
\hline P3 & SE \\
\hline P4 & VD+VS \\
\hline P5 & VD+VS \\
\hline P6 & VS+VR+SE \\
\hline P7 & VD+VS \\
\hline P8 & VD+VS \\
\hline
\end{tabular}

Nota: VD: Vegetação densa; VS: Vegetação secundária; VR: Vegetação rasteira; SE: Solo exposto.

Seguindo a direção do fluxo do rio Apeú encontra-se o terceiro ponto de referência, localizado no distrito do Apeú, com presença de remanescentes florestais, mas, são suprimidos pela classe de solo exposta (SE), principalmente pela presença da urbanização. Em contrapartida, observa-se que no ponto 4, apesar de haver uma predominância de vegetação densa e secundária (VD e VS), em sua margem esquerda, encontramse presenças de vegetação rasteira e solo exposto próximos à área de APP.

Nos pontos 5 e 6 são observados em seus limites de APP's que as margens direitas de ambos os pontos apresentam maior presença das classes de vegetação densa e secundária, enquanto que em suas 
margens esquerdas é notória a presença da classe de vegetação rasteira e solo exposto. Resultados discriminados pelas campanhas de campo, onde a classe de solo exposto e vegetação rasteira do ponto 5 é constituída por grameiras e plantação de mandioca. Enquanto que, no ponto 6 a classe de solo exposto vista na margem esquerda se refere ao núcleo urbano da agrovila de Macapazinho.

Em relação aos pontos 7 e 8, ambos possuem em seus limites de APP maior porcentagem das classes de vegetação densa e vegetação secundária. O que além de estar em concordância com o código florestal, favorece a conservação dos corpos hídricos. A conservação e proteção das APP's às margens dos corpos hídricos de uma bacia hidrográfica garantem a estabilização das margens dos rios, contribuindo no controle da qualidade da água por auxiliarem no controle do escoamento superficial, que causa erosão e arraste de nutrientes e sedimentos para os cursos d'água (EUGENIO et al., 2011; SILVA et al., 2017).

\section{Análise da espacialização da precipitação na sub-bacia hidrográfica do rio Apeú}

A integração dos objetivos relativos à conservação dos recursos naturais, biodiversidade e meio ambiente são apontadas por Silva et al. (2015), tendo em vista o planejamento e gerenciamento do uso e cobertura do solo objetivando a preservação e manutenção da biodiversidade e dos serviços ecossistêmicos.

Diante desse ponto de vista, associado aos aspectos e características descritos anteriormente, nesta secção do presente trabalho, será apresentado a integração das variáveis morfométricas, do uso e ocupação do solo e da precipitação (distribuição espacial) na SBHRA. Assim, é apresentado na figura 6, a distribuição da precipitação acumulada média anual, considerando o período de 2018 a 2019 (referentes às campanhas de campo), assim como, a espacialização da precipitação dos períodos chuvoso (dezembro a maio) e menos chuvoso (junho a novembro) da região de estudo.

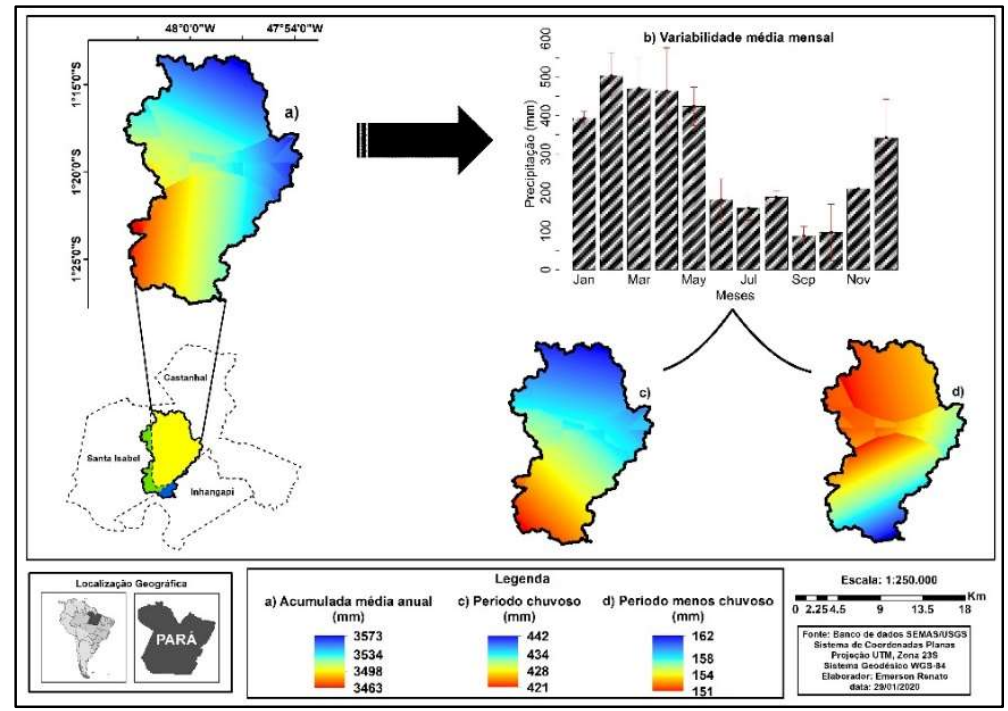

Figura 6: Distribuição espacial da: a) precipitação acumulada média anual, b) variabilidade média mensal, c) período chuvoso (dezembro a maio) e d) período menos chuvoso (junho a novembro) na SBHRA.

Observa-se que a precipitação acumulada média anual (figura 6a), tem uma distribuição dos maiores valores de precipitação nas porções norte e nordeste da sub-bacia, principalmente nas regiões de cabeceiras (presença das nascentes), atingindo valores superiores a $3.500 \mathrm{~mm}$ (máximo de $3.573 \mathrm{~mm}$ ) e mínimos de 
$3.463 \mathrm{~mm}$ ao sul-sudeste da sub-bacia. Ao analisar a figura 2, referente a hipsometria da sub-bacia, observase as maiores altitudes nas mesmas porções onde encontram-se os maiores índices de precipitação e que, apresentam baixa presença de vegetação, composta principalmente pelas classes de vegetação rasteira e solo exposto (figura 4).

Rocha et al. (2001), descrevem que a relação entre a precipitação e infiltração na área da bacia de drenagem é influenciada pela declividade associada à cobertura vegetal, uso do solo e que analisadas em conjunto estabelecem informações a respeito do grau de erosão presentes na bacia. Dessa maneira, com as informações de altitudes, declividade, uso e ocupação e precipitação, sugere-se que a parte norte da SBHRA pode apresenta condições desfavoráveis a infiltrações, favorecendo assim o escoamento superficial, resultando em erosão e carreamento de sedimentos e nutrientes às nascentes, assim como a supressão da vegetação remanescente.

Em relação ao comportamento da precipitação do período chuvoso (figura 6c), observa-se um comportamento análogo ao regime anual. Porém, o quantitativo da precipitação não apresentou diferenças significativas dentro da área da sub-bacia, com máximos e mínimos apresentando uma variação de $21 \mathrm{~mm}$. Tal comportamento de maior precipitação, associada com o uso predominante da classe de solo exposto, ao norte da sub-bacia, ressaltam a sobrecarga aos remanescentes florestais, principalmente nas áreas de nascentes presentes na sub-bacia.

Vale ressaltar que mesmo a porção sul da sub-bacia apresentando maiores porcentagens de classes de vegetação, todos os efeitos e alterações descritos ao norte (cabeceiras) serão refletidos nas partes mais baixas da bacia. Assim como, reflexos nos corpos hídricos e no seu tributário principal. Partindo desse conhecimento, até o presente momento foi observado que os valores elevados de precipitação se concentram ao norte da sub-bacia, nas regiões de maiores altitudes, fazendo com que efeitos ocorridos à montante sejam refletidos a jusante da sub-bacia.

Além disso, o comportamento da precipitação no período menos chuvoso (Figura 6d) apresenta configuração oposta ao período chuvoso, isto é, os maiores acumulados de precipitação ao sul, com máximos de $162 \mathrm{~mm}$, enquanto que os menores ao norte (mínimos de $151 \mathrm{~mm}$ ). Essa distribuição, favorece a análise não apenas da espacialização do acumulado médio, pois apesar de apresentar menor precipitação ao norte, a espacialização do período chuvoso e menos chuvoso permite um melhor conhecimento do comportamento da precipitação ao longo dos meses na sub-bacia, favorecendo as tomadas de decisões quanto à gestão e planejamento da sub-bacia.

\section{Vulnerabilidade ambiental da sub-bacia hidrográfica do rio Apeú}

Para que a análise de vulnerabilidade ambiental seja atrelada ao planejamento ambiental é essencial um estudo sistêmico de suas variáveis, proporcionando o conhecimento das áreas que necessitam maior preservação ou restrições e que carecem de ações diferenciadas por parte dos órgãos públicos (TROMBETA et al., 2014). Partindo desse posicionamento, as classes de vulnerabilidade ambiental da SBHRA e suas respectivas áreas estão distribuídas na tabela 10. 
É possível observar que a classe com maior representatividade é a vulnerabilidade baixa, aproximadamente $39,85 \%$, seguida das vulnerabilidades muito baixa e média, respectivamente $25,42 \%$ e 22,47\%. Enquanto que $12,26 \%$ da área da SBHRA é representada pela classe de vulnerabilidade alta. Somando-se a vulnerabilidade muito baixa, baixa e média, observa-se que a maior parte da sub-bacia, cerca de $87,74 \%$, está classificada dentro dessas classes de vulnerabilidade. Ou seja, a SBHRA correlaciona-se em sua maioria com áreas de menores riscos aos efeitos antrópicos (TREVISAN et al., 2018).

Tabela 10: Vulnerabilidade ambiental da sub-bacia hidrográfica do rio Apeú - SBHRA

\begin{tabular}{|c|c|c|}
\hline \multicolumn{3}{|c|}{ Vulnerabilidade Ambiental } \\
\hline Classes & Área $\left(\mathrm{km}^{2}\right)$ & Frequência (\%) \\
\hline Muito baixa & 79,18 & 25,42 \\
\hline Baixa & 124,14 & 39,85 \\
\hline Média & 70,01 & 22,47 \\
\hline Alta & 38,18 & 12,26 \\
\hline Total & 311,51 & 100 \\
\hline
\end{tabular}

Por meio da espacialização das classes de vulnerabilidade ambiental da SBHRA (figura 7), observa-se que as áreas de vulnerabilidade muito baixa e baixa (aproximadamente 65,27\% da área da SBHRA), distribuem-se conforme as classes de vegetação densa e secundária (com graus de vulnerabilidade baixos, respectivamente 1 e 1,5), apresentadas no mapa de uso e ocupação do solo (figura 4) e da tabela 8 , que representam as maiores porcentagens de ocupação na área da SBHRA, representando aproximadamente $55,25 \%$ da área total da sub-bacia. Feições distribuídas principalmente nas regiões planas e próximas ao corpo hídrico principal (rio Apeú), caraterizadas principalmente pelo tipo de vegetação Floresta densa aluvial $(G V=1)$ remanescentes florestais em estágios de sucessão ecológica ao sul da SBHRA $(G V=1,5)$, ou seja, distribuem-se em áreas com menores ações antrópicas.

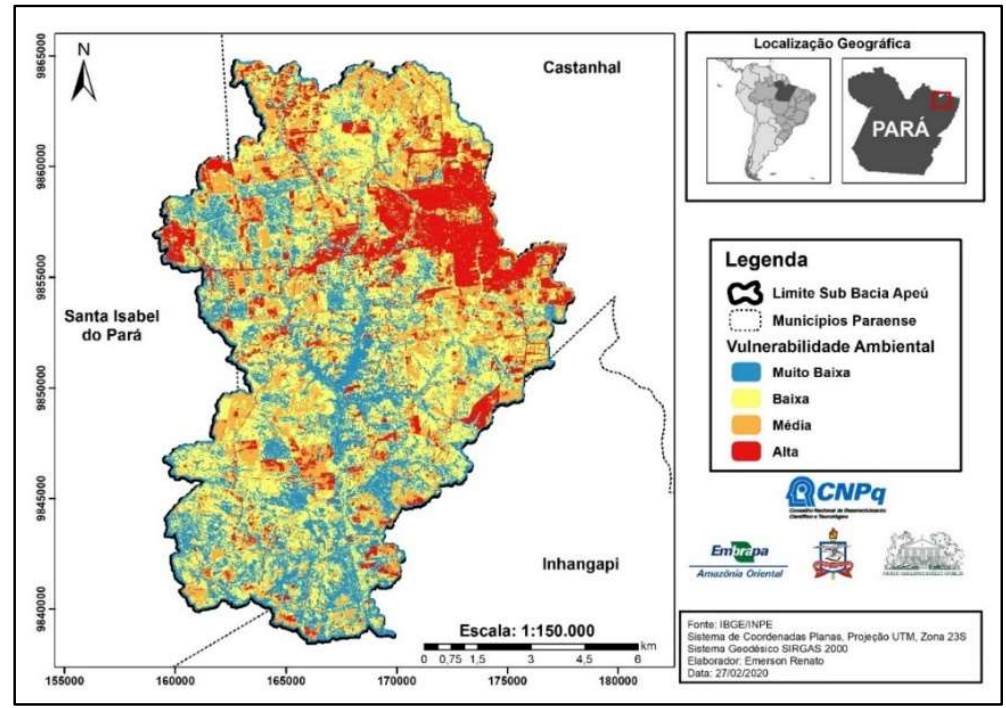

Figura 7: Mapa de vulnerabilidade ambiental da sub-bacia hidrográfica do rio Apeú - SBHRA.

A categoria vulnerabilidade ambiental média, representando $21,88 \%$ da área da sub-bacia, está distribuída principalmente no compartimento de coberturas de vegetação rasteiras, que apresenta grau de vulnerabilidade 2, destacando-se as pastagens e culturas presentes nos limites da SBHRA (figura 4). Classes que exercem maior pressão sobre as unidades remanescentes de vegetação secundárias e as margens dos 
corpos hídricos, sendo amplamente distribuída nas partes de maiores declividades/altitudes da SBHRA (grau de vulnerabilidade 2,5), promovendo principais alterações sobre as unidades geoambientais, e que já se apresentam mais próximas as áreas de influencias antrópicas.

Nas áreas de vulnerabilidade alta, aproximadamente 12,26\%, destacam-se a localização das unidades geológicas da Cobertura Detrito Laterítica Pleistocênica (grau de vulnerabilidade 3) e dos núcleos urbanos da cidade de Castanhal e agrovilas, caracterizadas principalmente pela classe de uso e ocupação de solo exposta $(G V=3)$ na SBHRA, composta pelas áreas urbanas e solos sem cobertura vegetal. Também caracterizada pelas classes de área antropizada, que possui grau de vulnerabilidade 3, e são situados principalmente à norte/nordeste da bacia, conforme mapa de uso e ocupação e de vulnerabilidade ambiental. Aspectos que resultam numa pressão negativa as características ambientais da sub-bacia e nas unidades geoambientais e, que evidenciam a correlação, mas acentuada às áreas de altos riscos aos efeitos da ocupação antrópica (COSTA et al., 2006; TREVISAN et al., 2018).

\section{CONCLUSÕES}

A determinação do índice de vulnerabilidade ambiental permitiu analisar o estado atual, em relação as alterações causadas pelas ações antrópicas na sub-bacia hidrográfica do rio Apeú (SBHRA), além de correlaciona-la com as informações morfométricas, de uso e ocupação do solo e da precipitação, encontradas na área de estudo.

A associação e discussão integrada apresentadas no presente trabalho, para a SBHRA, contribuem de maneira significativas para os conhecimentos das características do comportamento da precipitação, afetando principalmente as áreas ao norte/nordeste da SBHRA, que apresentaram maiores alterações por conta dos tipos de uso e ocupação do solo, assim como, maiores altitudes e maiores índices de precipitação (no período em estudo de 2018 a 2019). Foi possível também observar, que em muito dos pontos de referências, os limites de APP's não eram preservados, contribuindo assim para a degradação e alteração dos recursos naturais da SBHRA, em destaque a degradação do rio Apeú (corpo hídrico principal da sub-bacia).

As informações apresentadas incialmente, cruzadas com as variáveis geologia, pedologia e tipo de vegetação, permitiram a elaboração do mapa de vulnerabilidade ambiental da SBHRA. Diante disso, é possível observar que, em termos quantitativos (frequência), a SBHRA apresenta 65,27\% de sua área com distribuição de vulnerabilidades baixos e muito baixos. Porém, é nítido por meio da representação cartográfica da vulnerabilidade, uma distribuição acentuada dos fragmentos de vulnerabilidade médio, principalmente correlacionados as classes de pastagens e culturas, distribuídas quase sempre próximos às áreas de vegetação secundária ou densa, seguida pela distribuição da vulnerabilidade alta, correlacionada com às áreas antrópicas (núcleos urbanos), caracterizando a necessidade de ações frente a esses avanços de instabilidades ambientais na SBHRA.

Além disso, discussões e estudos relacionados a vulnerabilidade ambiental favorecem as tomadas de decisões frente a conservação e sustentabilidade dos recursos naturais, levando em consideração a capacidade de suporte de cada variável dentro do ecossistema, relacionadas principalmente as 
características especificas de cada ambiente natural. Fortalecendo a utilização, indiscutível, da bacia hidrográfica como unidade de planejamento e gestão.

AGRADECIMENTOS: ao CNPq, pela concessão de bolsa de mestrado ao primeiro autor; ao Programa de PósGraduação em Ciências Ambientais (PPGCA) da Universidade Federal do Pará.

\section{REFERÊNCIAS}

ALVARES, C. A.; STAPE, J. L.; SENTELHAS, P. C.; GONÇLAVES, J. L. M.; SPAROVEK, G.. Koppen's climate classification mao for Brazil. Meteorologische Zeitschrift, v.22, p.1-18, 2013. DOI: http://dx.doi.org/10.1127/0941-2948/2013/0507

ALVES, W. S.; MORAIS, W. A.; MARTINS, A. P.; AQUINO, D. S.; PEREIRA, M. A. B.; SALEH, B. B.. Análise do uso da terra, da cobertura vegetal e da morfometria da bacia do Ribeirão Douradinho, no sudoeste de Goiás, Brasil. Revista Brasileira de Geografia Física, v.12, n.03, p.1093-1113, 2019.

BELTRAME, A. V.. Diagnóstico do meio físico de bacias hidrográficas: modelo e aplicação. Florianópolis: UFSC, 1995.

BRASIL. Lei n.9433 de 08 de janeiro de 1997. Institui a Política Nacional de Recursos Hídricos, e dá outras providências. Brasília: DOU, 1997.

BRASIL. Lei n.12651 de 25 de maio de 2012. Dispõe sobre a proteção da vegetação nativa, e dá outras providências. Brasília: DOU, 2012.

CASTRO, P.; LOPES, J. D. S.. Recuperação e conservação de nascentes. Viçosa: Centro de Produções Técnicas, 2001.

CHRISTOFOLETTI, A.. Geomorfologia. 2 ed. São Paulo: Edgard Blücher, 1980.

CHRISTOFOLETTI, A.. Aplicabilidade do conhecimento geomorfológico nos projetos de planejamento. In: GUERRA, A. J. T.; CUNHA, S. B.. Geomorfologia: uma atualização de bases e conceitos. 11 ed. Rio de Janeiro: Bertrand Brasil, 2012.

CONAMA. Resolução n.423 de $\mathbf{1 2}$ de abril de 2010. Dispõe sobre parâmetros básicos para identificação e análise da vegetação primária e dos estágios sucessionais da vegetação secundária nos Campos de Altitude associados ou abrangidos pela Mata Atlântica. Brasília: CONAMA, 2010.

COSTA, F. H. S.; PETTA, R. A.; LIMA, R. F. S.; MEDEIROS, C. N. Determinação da Vulnerabilidade Ambiental na Bacia Potiguar, região de Macau (RN), utilizando Sistemas De Informações Geográficas. Revista Brasileira de Cartografia, v.2, p.119-127, 2006.

CREPANI, E.; MEDEIROS, J. D.; HERNANDEZ FILHO, P.; FLORENZANO, T. G.; DUARTE, V.; BARBOSA, C. C. F.. Sensoriamento remoto e geoprocessamento aplicados ao zoneamento ecológico-econômico e ao ordenamento territorial. São José dos Campos: INPE, 2001.

EMBRAPA. Sistema brasileiro de classificação de solos. 3 ed. Brasília: EMBRAPA, 2013.
EUGENIO, F. C.; SANTOS, A. R.; LOUZADA, F. L. R. O.; PIMENTEL, L. B.; MOULIN, J. V.. Identificação das áreas de preservação permanente no município de Alegre utilizando geotecnologia. Cerne, Lavras, v.17, n.4, p.563-571, 2011.

FAUSTINO, A. B.; RAMOS, F. F.; SILVA, S. M. P.. Dinâmica temporal do uso e cobertura do solo na Bacia Hidrográfica do Rio Doce (RN) com base em Sensoriamento Remoto e SIG: uma contribuição aos estudos ambientais. Sociedade e Território, Natal, v.26, n.2, p.18-30, 2014.

FEITOSA, T. B.; IOST, C.. Dinâmica hidrossedimentológica de duas sub-bacias hidrográficas localizadas no Estado do Tocantins. Revista Acadêmica: Ciências Agrárias e Ambiental, Curitiba, v.9, n.2, p.21-129, 2011.

FLORENZANO, T. G.. Geomorfologia: conceitos e tecnologias atuais. São Paulo: Oficina de Textos, 2008.

FRAGA, M. S.; FERREIRA, R. G.; SILVA, F. B.; VIEIRA, N. P. A.; SILVA, D. P.; BARROS, F. M.; MARTINS, I. S. B.. Caracterização Morfométrica da Bacia Hidrográfica do Rio Catolé Grande, Bahia. Nativa, Sinop, v.02, n.04, p.214-218, 2014. DOI: http://dx.doi.org/10.14583/2318-7670.v02n04a05

FUNK, C. PETERSON, P.; LANDSFELD, M.; PEDREROS, D.; VERDIN, J.; SHUKLA, S; HUSAK, G.; ROWLAND, J.; HARRISON, L.; HOELL, A.; MICHAELSEN, J.. The climate hazards infrared precipitation with Stations a new environmental record for monitoring extremes. Scientific data, v.2, p.150066, 2015.

HORTON, R. E.. Erosional development of streams and their drainage basins: hydrophysical approach to quantitative morphology. Geological Society of America Bulletin, v.56, n.3, p.275-370, 1945.

LANDIS, J. R.; KOCH, G. G.. The measurement of observer agreement for categorical data. International Biometric Society, v.33, n.1, p.159-174, 1977.

LOLLO, J. A.. O uso da técnica de avaliação do terreno no processo de elaboração do mapeamento geotécnico: sistematização e aplicação na quadrícula de Campinas. Tese (Doutorado em Geotecnia) - Universidade de São Paulo, São Carlos, 1995

MENDES, A. T.. Delimitação da bacia hidrográfica do Rio Santo Antônio pela ferramenta de delimitação automática TauDEM. Revista Brasileira de Geografia Física, v.11, n.03, p.973-986, 2018.

RIBEIRO, B. M. G.; KUX, H. J. H.. Classificação Orientada a Objeto para Mapeamento do Uso do Solo: métodos de 
análise de expansão urbana. In: SIMPÓSIO BRASILEIRO DE SENSORIAMENTO REMOTO, 14. Anais. Natal, 2009.

ROCHA, J. S. M.; KURTZ, S. M. J. M.. Manejo integrado de bacias hidrográficas. 4 ed. Rio Grande do Sul: Santa Maria, 2001.

RODRIGUES, B. M.; OSCO, L. P.; ANTUNES, P. A.; RAMOS, A. P. M.. Avaliação da influência do uso e cobertura da terra na qualidade das águas superficiais da bacia hidrográfica do rio Pirapozinho (SP). Revista Brasileira de Geografia Física, v.12, n.03, p.738-753, 2019.

RODRIGUES, R. S. S.; FERNANDES, L. L.; CRISPIM, D. L.; VIEIRA, A. S. A.; PESSOA, F. C. L.. Caracterização morfométrica da bacia hidrográfica do Igarapé da Prata, Capitão Poço, Pará, Brasil. Revista Verde de Agroecologia e Desenvolvimento Sustentável, v.11, n.3, p.143-150, 2016.

RODRIGUES, M. T.; CARDOSO, L. G.; CAMPOS, S.; RODRIGUES, B. T.; BARROS, Z. X.. Comportamento do Software Terraview na Classificação Supervisionada em Diferentes Bacias. Energ. Agric, v.31, n.3, p.282-290, 2016.

SANTOS, R. F.. Planejamento ambiental: teoria e prática. São Paulo: Oficina de Textos, 2004

SANTOS, G. V.; DIAS, H. C. T.; SILVA, A. P. S.; MACEDO, M. N. C.. Análise hidrológica e socioambiental da bacia hidrográfica do Córrego Romão dos Reis, Viçosa/MG. Revista Árvore, Viçosa, v.31, n.5, p.931-940, 2007.

SANTOS, D. B.; VIDOTTO, M. L.; BERTINATTO, R.; SOUZA MARCON, G. R.; FRIGO, E. P.. Caracterização morfométrica da Bacia Hidrográfica do Rio São José, Cascavel, PR. Revista Brasileira de Tecnologia Aplicada nas Ciências Agrárias, Guarapuava, v.5, n.2, p.7-18, 2012.

SILVA, C. J.; SOUZA, K. N. S.; IKEDA-CASTRILLON, S. K.; LOPES, C. R. A. S.; NUNES, J. R. S.; CARNIELLO, M. A.; MARIOTTI, P. R.; LAZARO, W. L.; MORINI, A.; ZAGO, B. W.; FAÇANHA, C. L.; ALBERNAZ-SILVEIRA, R.; LOUREIRO, E.; VIANA, I. G.; OLIVEIRA, R. F.; CRUZ, W. J. A.; ARRUDA, J. C.; SANDER, N. L.; FREITAS JUNIOR, D. S.; PINTO, V. R.; LIMA, A. C.; JONGMAN, R. H. G.. Biodiversity and its drivers and pressures of change in the wetlands of the Upper Paraguay/Guaporé Ecotone, Mato Grosso (Brazil). Land Use Policy, v.47, p.163-178, 2015. DOI: http://doi.org/10.1016/j.landusepol.2015.04.004

SILVA, D. C. C.; FILHO, J. L. A.; SALES, J. C. A.; LOURENÇO, R. W.. Uso de indicadores morfométricos como ferramentas para avaliação de bacias hidrográficas. Revista Brasileira de Geografia Física, v.09, n.02, p.627-642, 2016.

SILVA, M. S.; BUENO, I. T.; JÚNIOR, F. W. A.; BORGES, L. A. C.; CALEGARIO, N.. Avaliação da cobertura do solo como indicador de gestão de recursos hídricos: um caso de estudo na sub-bacia do Córrego dos Bois, Minas Gerais. Engenharia Sanitária e Ambiental, v.22, n.3, p.445-452, 217. DOI: https://doi.org/10.1590/s1413-41522017149673

SOUZA, S. R.; MACIEL, M. N. M.; OLIVEIRA, F. A.; JESUÍNO, S. A.. Dinâmica da paisagem na bacia hidrográfica do Rio Apeú, nordeste do Pará, Brasil. Rev. Acad. Ciênc. Agrár. Ambient, Curitiba, v.9, n.2, p.141-150, 2011.

STRAHLER, A. N.. Hypsometric (area-altitude) analysis of erosional topography. Geological Society of America Bulletin, v.63, n.11, p.1117-1142, 1952.

SUMMERFIELD, M. A.. Global Geomorphology: an introduction of the study of landforms. New York: Longman Scientific \& Technical, 1991

SWAROWSKY, A.; DAHLGREN, R. A.; TATE, K. W.; HOPMANS, J. W.; O'GEEN, A. T.. Catchment-Scale Soil Water Dynamics in a Mediterranean-Type Oak Woodland. Vadose Zone Journal, v.10, p.800-815, 2011. DOI: http://dx.doi.org/10.2136/vzi2010.0126

TONELLO, K. C.. Análise hidroambiental da bacia hidrográfica da cachoeira das Pombas, Guanhães, MG. Tese (Doutorado em Ciências Florestal) - Universidade Federal de Viçosa, Viçosa, 2005.

TREVISAN, D. P.; MOSCHINI, L. E.; DIAS, L. C. C.; GONÇALVES, J. C.. Avaliação da Vulnerabilidade Ambiental de São Carlos SP. Rev. RAEGA, Curitiba, v.44, p.272-288, 2018.

TROMBETA, L. R.; GARCIA, R. M.; NUNES, R. S.; GOUVEIA, I. C. M. C.; LEAL, A. C.. Análise da fragilidade potencial e emergente do relevo da unidade de gerenciamento de recursos hídricos pontal do Paranapanema, São Paulo, Brasil. Caderno de prudentino de geografia, n.36, p.159-173, 2014.

VALE, J. R. B.. Análise geoambiental da bacia hidrográfica do rio Apeú, Nordeste Paraense: subsídios ao planejamento ambiental. Dissertação (Mestrado em Geografia) Universidade Federal do Pará, Belém, 2017.

VALE, J. R. B.; BORDALO, C. A. L.. Análise Multitemporal Do Uso da Terra e da Cobertura Vegetal entre 1985 e 2015 na Bacia Hidrográfica do Rio Apeú, Nordeste Paraense. Revista GeoAmazônia, Belém, v.5, n.10, p.23-40, 2017.

VILLELA, S. M.; MATTOS, A.. Hidrologia aplicada. São Paulo: Mc Graw-Hill, 1975.

VILELA FILHO, L. R.; VITTE, A. C.. A utilização de técnicas morfométricas do relevo aplicadas na determinação da fragilidade ambiental: o caso da bacia do córrego Proença, município de Campinas (SP). In: ENCONTRO DE GEÓGRAFOS DA AMÉRICA LATINA, 10. Anais. São Paulo: USP, 2005.

A CBPC - Companhia Brasileira de Produção Científica (CNPJ: 11.221.422/0001-03) detém os direitos materiais desta publicação. Os direitos referem-se à publicação do trabalho em qualquer parte do mundo, incluindo os direitos às renovações, expansões e disseminações da contribuição, bem como outros direitos subsidiários. Todos os trabalhos publicados eletronicamente poderão posteriormente ser publicados em coletâneas impressas sob coordenação da Sustenere Publishing, da Companhia Brasileira de Produção Científica e seus parceiros autorizados. Os (as) autores (as) preservam os direitos autorais, mas não têm permissão para a publicação da contribuição em outro meio, impresso ou digital, em português ou em tradução. 